\title{
Preliminary in vitro Evaluation of a Semisynthetic Oestrogen Polymer-based Formulation
}

\author{
CRINELA UTESCU ${ }^{1 *}$, DELIA BERCEANU-VADUVA ${ }^{1 *}$, CONSTANTIN TUDOR LUCA ${ }^{1 *}$, CLAUDIA FARCAS $^{2}$, \\ VICTOR DUMITRASCU', MATILDA RADULESCU ${ }^{1}$ \\ ${ }^{1}$ Victor Babes University of Medicine and Pharmacy, Faculty of Medicine, Eftimie Murgu 2, 300041, Timisoara, Romania \\ 2Victor Babes University of Medicine and Pharmacy, Faculty of Pharmacy, Eftimie Murgu 2, 300041, Timisoara, Romania
}

\begin{abstract}
Oestrogen hormones playkeyroles in the human body, are involved in complex mechanisms, both beneficial and unwanted. Because semisynthetic oestrogens are commonly used today in various hormonal therapies, they has inevitably been linked to the appearance of certain carcinogenic processes, which are primarily based on oestrogen-based drugs, either as initiators or promoters. A promising alternative that can help reduce unwanted effects is to capture the active substance in a polymeric matrix that is capable of retaining its biological activity. In this study, activity on the viability of breast cancer cells with expressed oestrogen receptors of a polymeric formulation with ethinylestradiol and polylactic acid was evaluated.
\end{abstract}

Keywords: semisynthetic oestrogen, polymer particles, breast cancer, cell

Due to population growth, food consumption focused on providing micro and macro nutrients has increased exponentially and directly proportional to the synthesis of chemicals, thus creating a strong link between diet and pharmaceuticals focused on preventing or curing disease [1]. This link is an extremely complex one, which is often accompanied by a number of adverse effects in the most serious situations even irreversible.

Natural oestrogens, represented in figure 1, have the ability to suppress ovulation and, together with progestogens, are commonly used in contraception and hormone replacement therapy. On the other hand, they are also used to: supplement the natural levels of oestrogen in situations where they are low (some menstrual disorders); suppressing androgen formation (reducing the risk of developing prostate cancer); protection against osteoporosis and stroke [2]. The role of hormone replacement therapy (HRT) has been debated for years and the findings are often contradictory. Some observational data indicate many benefits, including attenuation of heart disease and mortality, and others indicate an increased risk of heart disease and breast cancer. These data led to a sharp decrease in HRT use. Therefore, exact protocols are needed regarding the age at which hormone replacement therapy is initiated and its composition. The therapy should be based primarily on
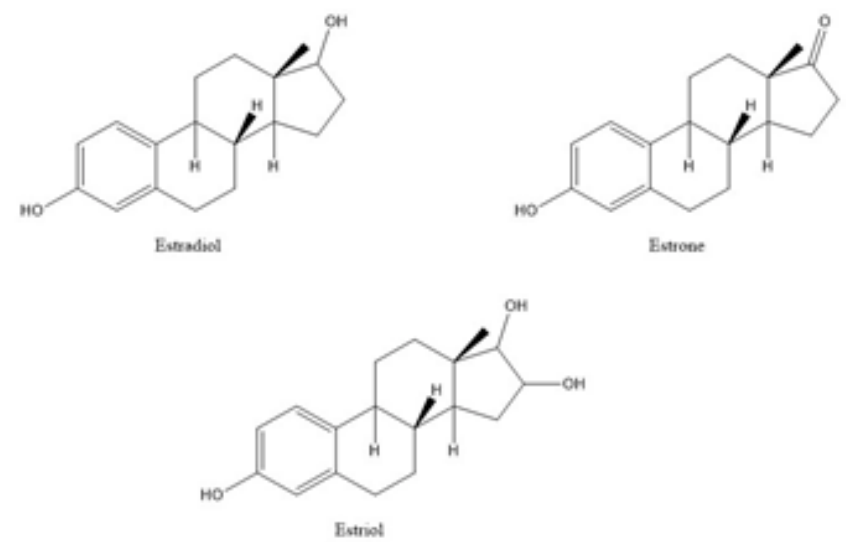

Fig. 1. Chemical structures of natural oestrogens oestrogen, taking into account the fact that various studies present benefit with oestrogen alone compared to association between oestrogen and progestogen [3]. Research in the field over the past few years has not yet fully elucidated the link between oestrogen and the appearance and development of breast and endometrial cancer. Also, must be consider the evidence that prolonged exposure to different types of oestrogens is a major risk factor in declassing their associated cancers [4].

Ethinylestradiol (EE), a semisynthetic derivative of natural oestrogens, is more active than this because the $17 \alpha$-ethinyl group prevents the oxidation of the 17 $\beta$-hydroxy group, and $17 \alpha$-ethinyl can be oxidized, with the formation of a highly reactive intermediate compound that leads to irreversible inhibition of CYP enzymes involved in the metabolism of steroids [5]. Also, drug-drug interactions that occur due to $\mathrm{EE}$ fall into one of the following situations: (i) EE may behave as a drug victim and the pharmacokinetic profile is affected by drugs administered simultaneously by inhibiting or inducing metabolism and (ii) the compound can either inhibit or induce metabolic drug enzymes behaving as an initiator of drug interactions [ 6]. In order to reduce the necessary doses to be administered in various diseases and at the same time counteract the adverse effects associated with clinical manifestations and fooddrug or drug-drug interactions, it is necessary to obtain stable formulations which maintain the pharmacological properties of the active substances. In the last decade, studies of controlled release formulations of active substances have intensified precisely due to: a) repeated dosing (resulting in a deformation of the drug concentration), b) the occurrence of toxic side effects due to increased concentration, and ) rapid decrease in the level of active substance aw ay from the therapeutic target [7].

The present study was conducted in order to obtain a preliminary evaluation of the behaviour of normal and breast cancer tumoral cells after stimulation with ethinylestradiol and ethinylestradiol polylactic acid nanoparticles (EENPs). 


\section{Experimental part}

\section{Materials and methods}

Ethinylestradiol, polylactic acid (PLA), polyvinyl alcohol (PVA), organic solvents and other reagents utilized in the study were purchased from Sigma-Aldrich (Germany).

Ehinylestradion nanoparticles (EENPs) were obtained as described in the literature, with minor modifications [8]. Briefly, were prepare the two phases: PLA and EE (molar ration $5: 1 \mathrm{w} / \mathrm{w}$ ) were dissolved in acetone - organic phase and PVA was dissolved in water (1:100 w/v) - aqueous phase. Subsequently, the organic phase was injected into the aqueous phase under magnetic stirring at room temperature, with the formation in time of the EENPs. Acetone was removed on a rotary evaporator and the resulted EENPs was stored at $2-6^{\circ} \mathrm{C}$, protected from light until further determinations. Blank formulation (without ethinylestradiol) were prepared in the same manner. Characterization of nanoparticles was realized by using common techniques such as: Dynamic light scattering (to assess the size of particles and polydispersity index), Zeta potential (to evaluate the stability of particles) and spectrophotometry (to see drug loading capacity) [9]. All the determinations were made at room temperature and in triplicate.

The $\mathrm{HaCaT}$ cell line (immortalized human keratinocytes) was acquired from Cell Lines Service $\mathrm{GmbH}$ (CLS) while MCF-7 cell line (human breast adenocarcinoma) was acquired from the American Type Culture Collection (ATCC). The cells were cultured in specific media -HaCaT in Dulbecco's modified Eagle Medium and MCF-7 in Eagle's Minimum Essential Medium -and were treated, according to culture protocols, with $10 \%$ fetal bovine serum and antibiotic mixture. The cells were kept at $37^{\circ} \mathrm{C}$ in an atmosphere with $5 \%$ carbon dioxide.

The cell viability was evaluated by using a colorimetric assay - Alamar blue [10]. In short, 10,000 cells/ well were treated with various concentrations of EE and EENPs, respectively $(0.1,1,10,25$ and $50 \mu \mathrm{g} / \mathrm{mL})$ and a volume of Alamar blue was added and maintained for three hours. Absorbance was read at 570 and $600 \mathrm{~nm}$ on XMark $^{\text {TM }}$ Microplate Spectrophotometer. Control cells are treated with DMSO because it is the solvent used in the preparation of the dilutions of samples.

\section{Results and discussions}

Taken as a whole, the physicochemical properties, size, shape, surface loading, and coating etc. of nanoparticles, are key elements in interactions with the immune system, with different specific mechanisms of action [11].

In the table 1 are related the data regarding specific characteristics of EENPs. As can be seen, according to the obtained values, the synthesized nanoparticles correspond to their preliminary use in pharmaco-medical applications.

Based on the fact that EE presents two different wavelengths of absorption in UV spectrum ( 215 and 280 $\mathrm{nm}$ ) the drug loading capacity was assessed by the estimation of $E E$ content from the supernatant and $E E$ content after centrifugation and the measurements were conducted at $280 \mathrm{~nm}$ by using UV/visible spectroscopy. At different time interval (ranging from 1 to 14 days) the loading efficiency was between 20 and $31 \%$.

Preclinical studies are based on the first phase on cell line behaviour in the presence of compounds requiring pharmaco-toxicological assessments. Healthy cells are used to evaluate the potential toxicity of the compounds. In this experimental research, a stimulating effect on keratinocytes cells was observed, especially when using nanoparticles at the lowest concentrations tested (fig. 2). A number of studies have highlighted the beneficial and protective effects of oestrogens in skin disorders - healing certain wounds, providing protection against photosensitisation, increasing epidermal thickness, improving inflammatory affections [12,13].

The MCF-7 cell line is most commonly used in the study of the ER-positive mechanisms of breast cancer cells due to its resistance to therapy acquired through use. Thus, cells are optimal for the study of resistance to anti-hormone therapy, being easy to cultivate and stimulate while retaining ER expression [14]. In the present study, the test compounds did nothave a noticeable influence on the cells: ethinylestradiol at the lowest concentrations had a stimulating effect on the cell while at the highest concentration the viability was around $94 \%$. The ethinylestradiol-based polymer kept the compound influences at low concentrations and at the highest concentration reduced cell viability to $90 \%$ (fig. 3 ).

\begin{tabular}{|c|c|c|c|}
\hline \multirow[t]{2}{*}{ Compound } & \multicolumn{2}{|c|}{ Dimenssion $(\mathrm{nm})$} & \multirow{2}{*}{$\begin{array}{c}\text { Zeta potential }(\mathrm{mV}) \\
\text { Average } \pm S E\end{array}$} \\
\hline & Average \pm SE & Polydispersity index $\pm \mathrm{SE}$ & \\
\hline Blank_NPs & $181=0.32$ & $0.253 \pm 0.012$ & - \\
\hline$E E \bar{N} P_{s}^{-}$ & $232=3.79$ & $0.224 \pm 0.004$ & $-28.5=0.9$ \\
\hline
\end{tabular}

Table 1

PHYSICOCHEMICAL CHARACTERISTICS OF ETHINYLESTRADIOL POLYLACTIC ACID NANOPARTICLES

$\mathrm{HaCaT}$

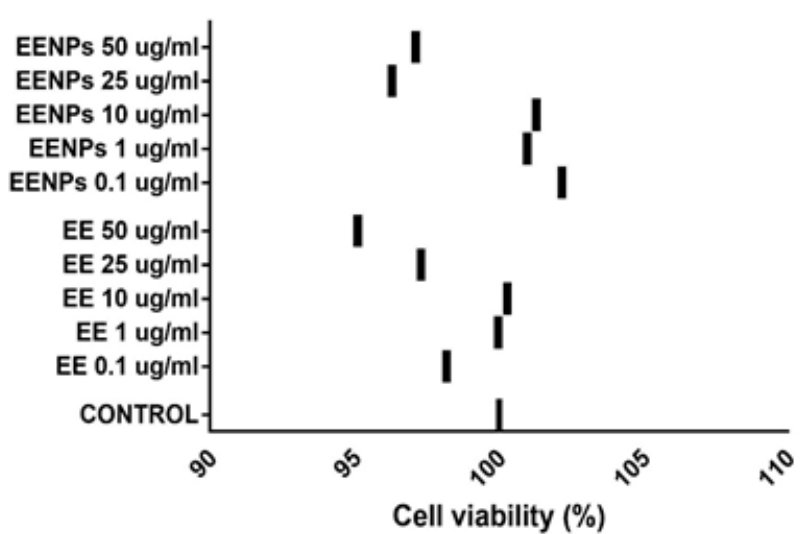

Fig.2. Percentage of viable keratinocytes cells after stimulations with test compounds
MCF 7

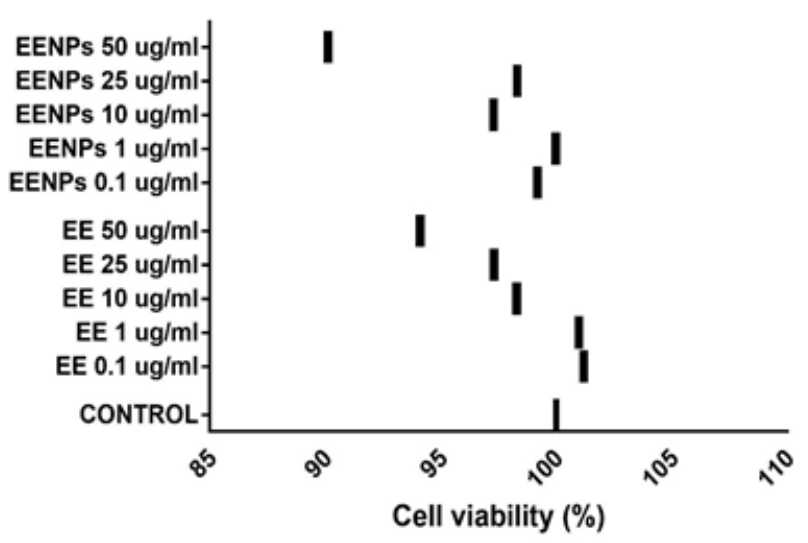

Fig. 3. Percentage of viable breast cancer cells after stimulations with test compounds 
Biological activity and oestrogen-induced effects are based on two types of mechanisms: genomic (mediated by interactions with nuclear oestrogen receptors, ER $\alpha$ and $E R \beta$ ) and non-genomic (mediated by cell membrane receptors associated with $\mathrm{G}$ protein activators of intracellular signals) [5]. Some researchers have demonstrated the presence of $E R \alpha$ and $E R \beta$ in the human MCF-7 cell mitochondria and have deepened the mechanisms involved by claiming that the nuclear and mitochondrial proteins of the tumor cells from the study bind to several responsive estrogenic elements [15].

\section{Conclusions}

Polymers are extremely useful formulations in addressing new therapies that have beneficial effects with the reduction of side effects. Ethinylestradiol is an intensely studied compound because it exerts a number of effects both in terms of contraception, hormonal substitution therapy and the food/drug-drug interactions. Therefore, in order to continue to benefit from the positive effects induced by it, it is necessary to find formulations that keep pharmacological activity but which reduce the unwanted effects. PVA is a suitable compound to obtain stable and effective ethinylestradiol nanoparticles and establish involvement in the occurrence of cancer. Further, breast cancer cell lines such as MCF-7 are expected to be at the basis of research into the treatment of these malignant disease. The data obtained is necessary to correlate certain factors in order to find the ideal in vivo model that is effective in many ways: medical, economic and social.

\section{References}

1. DE BOER, A., VAN HUNSEL, F., BAST, A. Regul. Toxicol. Pharmacol., 73, 2015, p. 859.

2. TAPIERO, H., NGUYEN BA, G., TEW, K. Biomed. Pharmacother., 56, no. 1, 2002, p. 36.

3. LOBO, R.A. Nat. Rev. Endocrinol., 13, 2017, p. 220.

4. TSUCHIYA, Y., NAKAJIMA, M., YOKOI, T. Cancer Lett., 227, 2005, p. 115.

5. KUHL, H. Climacteric, 8, no. 1, 2005, p. 3.

6. ZHANG, H., CUI, D., WANG, B. et al. Clin. Pharmacokinet., 46, no. 2 , 2007, p. 133.

7. SCHNEIDER, C., LANGER, R., LOVEDAY, D., HAIR, D., J. Control. Release, 262, 2017, p. 284.

8. MA, X., CHENG, Z., JIN, Y. et al. Biomaterials, 35, no. 9, 2014, p. 2878.

9. MUNTEANU, M.F., ARDELEAN, A., BORCAN, F. et al. Curr. Drug Deliv., 14, no.8, 2017, p. 1178.

10. PREDA, M., CHEVERESAN, A., PInZARU, I. et al. Rev. Chim.(Bucharest), 69, no. 7, 2018, p. 1907.

11. PINZARU, I., CORICOVAC, D., DEHELEAN, C. et al. Food Chem. Toxicol., 111, 2018, p. 546.

12. CARNESECCHI, J., MALBOUYRES, M., DE METS, R. et al. PLOS ONE 10, 2015, e0120672.

13. CORICOVAC, D., FARCAS, C., NICA, C. et al. Int. J. Mol. Sci., 19, 2018, 3600.

14. SWEENEY, E.E., MCDANIEL, R.E., MAXIMOV, P.Y, et al. Horm. Mol. Biol. Clin. Investig., 9, 2013, p. 143.

15. CHEN, J.Q., ESHETE, M., ALWORTH, W.L., YAGER, J.D. J. Cell. Biochem., 93, no. 2, 2004, p. 358.

$\overline{\text { Manuscript received: } 19.12 .2018}$ 